Article

\title{
Spiritual Distress in Bereavement: Evolution of a Research Program
}

\author{
Laurie A. Burke * and Robert A. Neimeyer \\ Department of Psychology, University of Memphis, Memphis, TN 38152, USA; \\ E-Mail: neimeyer@memphis.edu
}

* Author to whom correspondence should be addressed; E-Mail: laburke@memphis.edu; Tel.: +1-901-438-9669.

External Editor: Arndt Büssing

Received: 15 September 2014; in revised form: 21 October 2014 / Accepted: 31 October 2014 / Published: 12 November 2014

\begin{abstract}
Many mourners turn to their spiritual beliefs and traditions when confronted by the death of a loved one. However, prior studies have either focused primarily on the benefits of faith following loss or studied spiritual struggle outside the context of bereavement. Moreover, scales to measure bereavement-related crises of faith and interventions specifically designed for spiritually inclined, distressed grievers are virtually non-existent. Our program of research, which to date has consisted of working with Christian grievers and is outlined below, elucidates complicated spiritual grief (CSG) - $\mathrm{a}$ spiritual crisis following the loss of a loved one. For example, our longitudinal examination of 46 African American homicide survivors established the relation between positive religious coping, $\mathrm{CSG}$, and complicated grief (CG), to clarify whether religious coping more strongly predicted bereavement distress or vice versa, with a follow-up study that determined the relation between religious coping and posttraumatic stress disorder (PTSD) and depression. We replicated and expanded these findings with a diverse sample of 150 grievers to explore the complex relation between $\mathrm{CSG}, \mathrm{CG}$, and meaning making in a comparison study of mourners who had experienced traumatic-versus natural death losses. In a companion study, we qualitatively analyzed 84 grievers' narratives and interviewed a 5-member focus group to capture and learn from their firsthand experiences of spiritual distress. To close the gap in terms of CSG assessment, we also developed and validated the Inventory of Complicated Spiritual Grief (ICSG). Currently, our ongoing CSG investigation extends in several directions: first, to a sample of family members
\end{abstract}


anticipating the loss of their hospice-eligible loved one in palliative care; and, second, to the development and testing of a writing-intensive intervention for newly bereaved, spiritually inclined grievers.

Keywords: religious coping; religious struggle; spiritual crisis; complicated spiritual grief; bereavement; complicated grief; PTSD; meaning making; African American; homicide

\section{Introduction}

Grief in the form of turbulent emotions, separation distress, and preoccupation with memories of the deceased is a nearly universal response to the death of a loved one. Yet, at least when losses result from natural causes and are otherwise normative, nearly half of the bereaved individuals respond with characteristic resilience, with distress subsiding rather quickly [1]. Other mourners continue to experience acute grief symptoms for a year or two after the loss, but ultimately cope adaptively [2]. However, evidence also exists that a subset of grievers struggles markedly and for a prolonged period, evidencing a profoundly disruptive grief response known as complicated grief (CG) $[3,4]$ prolonged grief disorder (PGD) [5,6] or persistent complex bereavement disorder [7]. Particularly when death occurs suddenly as a result of suicide, homicide, or fatal accident [8] intense and life-limiting grief can persist for years with little evident adaptation to the loss [9]. Such complications in grieving seem to occur more frequently for ethnic groups suffering greater social disadvantage [10], partly as a function of the greater likelihood of suffering the traumatic and violent death of loved ones [11].

Religion and spirituality ${ }^{1}$ for many individuals extends beyond a "means of coping" to a "way of being" that is foundationally rooted in every aspect of the individual's living and dying processes $[12,13]$. Religion and spirituality also play a centrally important role in adapting to loss for many grievers [14,15], including groups such as African Americans [16] who more frequently confront tragic loss [17]. For such groups, faith appears to buffer the effects of loss [18] by reinforcing hope for reunion with their loved one in the afterlife, offering a sense of divine consolation, and extending the support of a community of fellow believers. In addition, although research results are mixed, Exline and Rose's (2013) [19] overview highlights recent studies with diverse samples that exemplify spiritual growth emerging from spiritual crisis (see also [20,21]). And yet, when mourners experience $\mathrm{CG}$ and its attendant separation distress, confusion about their role in life, or an inability to accept the loss [22,23], the griever's faith can be called into question, challenging one's sense of secure connection to both God and the religious community.

Over the last decade social scientists have begun to explore the concepts of spiritual struggle [24] and spiritual crisis [25] in distressed grievers. However, much of this work has studied religious coping in cross-sectional studies (see [15], for full review), often assuming that drawing on spirituality softens complications in grief. Quite recent research, however suggests that the opposite relation could be at least as significant, as bereavement distress can forecast later spiritual struggle [26].

1 Although not synonymous, spirituality and religion are used interchangeably throughout this study for sake of simplicity in reporting research. 
Our goal in the present article is to review our program of research on spiritual struggle in bereavement, particularly but not exclusively in the anguishing circumstance of homicide loss in the African American community. However, we will also situate this specific attention to the challenges faced by Christian mourners in a fuller consideration of contemporary bereavement research, which both informs our work and is in turn informed by it.

\subsection{Bereavement Outcomes}

Research has shown that major depressive disorder (MDD) represents a common form of bereavement distress [2]. However, other forms of distress, such as posttraumatic stress disorder (PTSD [2] and CG [3]) have been shown to have incremental validity in predicting bereavement outcome [22,27,28], arguing for a more comprehensive assessment of adaptation following loss.

Complicated grief entails prolonged grieving, reflected in profound and preoccupying separation distress, psychologically disturbing and intrusive thoughts of the deceased, a sense of emptiness and meaninglessness, trouble accepting the reality of the loss, and difficulty in envisioning a life without the deceased loved one [29]. Positioned at the extreme end of a continuum that also encompasses more normative responses to loss [30], CG occurs in approximately $10 \%$ of the general bereaved population [28]. However, recent studies document much higher prevalence rates in vulnerable groups. These include African American cancer caregivers, with CG rates of 22\% [31], bereaved parents, with rates of 30\% [32], victims of terrorism, with rates of 44\% [33], African American homicide survivors, with rates of 55\% [34], and suicide survivors, with rates of 70\% [35]. In particular, recent studies have established that violent death is a potential risk factor for CG $[8,32,36]$ and have associated CG with a spiritual struggle in meaning making regarding the loss [37]. With a greatly higher homicide rate for African Americans than Caucasians [38], these findings call for more research on how spiritually inclined individuals in that community adjust to violent death losses.

\subsection{Risk Factors for Complicated Grief}

The multidimensional nature of adaptation to loss poses challenges to the identification of risk factors predicting prolonged and intense grieving. Viewing grief in dimensional terms (i.e., existing on a continuum where differences between grievers whose response to loss warrants treatment and those whose do not are reflected in the duration and intensity of symptoms and levels of impairment, not in distinctive symptoms), Burke and Neimeyer [39] systematically examined studies that explored antecedents and predictors of CG. We identified more consistent prospective predictors of intense grieving, as well as those that were potential factors in forecasting grief outcomes.

Risk factors that emerged as most salient included: (1) low levels of social support; (2) avoidant/anxious/insecure attachment style; (3) discovering the body (in cases of violent death) or dissatisfaction with death notification; (4) being a spouse or a parent of the deceased; (5) high levels of pre-death marital dependency; and (6) high levels of neuroticism. Inasmuch as CG is conceptualized as an attachment-based disorder, with symptomatology indicative of separation distress and preoccupation with the deceased, it is understandable that mourners who are vulnerable to feeling abandoned and alone, who suffer from excessive anxiety or obsession, and who lose a security-enhancing or care-providing 
relationship, under conditions of minimal support, and perhaps in circumstances that leave them struggling with post-traumatic imagery, would be especially prone to the development of CG.

In addition to these primary conclusions, studies in Burke and Neimeyer's review [39] further suggested that being young, being non-Caucasian, having less education, little income, prior losses, or losing a child of any age to a violent, sudden death tends to predict prolonged and intense grief.

\subsection{Spiritual Coping}

People vary in their response to loss $[22,40]$ just as they differ in how they cope with stress in general [41]. As one important subset of coping responses, positive religious coping (PRC) has been conceptualized by Pargament, Smith, Koenig, and Perez as: "an expression of a sense of spirituality, a secure relationship with God, a belief that there is meaning to be found in life, and a sense of spiritual connectedness with others" ([42], p. 712). Negative religious coping (NRC), on the other hand, refers to "spiritual discontent, punishing God reappraisals, interpersonal religious discontent, demonic reappraisals (attributing the event to the work of the devil), and reappraisals of God's power" ([42], p. 710). Importantly, Hills, Paice, Cameron, and Shott [43] and Pargament, Koenig, Tarakeshwar, and Hahn [44] found that it is commonplace for individuals to use both PRC and NRC at the same time, a phenomenon confirmed in more recent samples, as outlined below.

What role does religious coping have in helping mourners adapt to loss? One possibility is that it provides an avenue for finding meaning [45], reasserting control of a stressful situation, petitioning God's comfort and closeness, seeking support from like-minded others who share one's spiritual orientation, and transforming one's life in the wake of loss [46]. Likewise, Büssing and Koenig [47] stressed the importance of spiritual coping for sufferers of chronic illness. They outlined four core dimensions of spiritual needs: Connection, Peace, Meaning/Purpose, and Transcendence, which might be influential in fostering recovery for seriously ill patients, as well as those coping with the losses of loved ones.

Evidence suggests that religious coping is particularly characteristic of African Americans [18], who endorse spirituality at rates significantly higher than do Caucasians [16]. Yet in the very few studies that have examined religious coping specifically as it relates to grief, most have focused exclusively on the benefits of spirituality in the wake of loss [14,15]. Thus, understanding how the condition of being bereaved might subsequently affect one's spirituality is grossly under-explored, particularly in those ethnic groups most likely to cope with loss in religious terms.

One obvious resource of a spiritual kind that mourners draw on at difficult times involves turning toward their spiritual community, a factor that has been associated with better bereavement outcomes [48-50]. However, other studies document that grievers do not always feel ministered to by their spiritual community. For example, Richardson and Balaswamy [51] found that widowers who regularly attended church services had less positive and more negative affect than those who attended irregularly. One plausible explanation is suggested by mourners who report a sense of abandonment by others while they are grieving, or in some cases enduring negative interactions that complicate an already difficult bereavement [52].

Across a range of studies, results bearing on the role of religious coping with bereavement have been contradictory. For example, positive spiritual coping was associated with better adjustment 
following the loss of a child who died in the pediatric intensive care unit [53]. In contrast, Tarakeshwar, Hansen, Kochman, and Sikkema's [54] study of 252 HIV-positive mourners found that individuals who used more PRC reported higher levels of grief. Anderson, Marwit, Vandenberg, and Chibnall [55] uncovered similar, albeit more complex, results. In their study of 57 mothers who lost a child to sudden, violent death, or other fatality, they found that neither NRC nor PRC was statistically related to grief when assessed alone. Instead, an interaction effect emerged, indicating that mothers who used PRC in tandem with task-oriented coping fared better in terms of their grief. In a cross-sectional study of 150 homicidally bereaved individuals, Thompson and Vardaman [56] found that their predominantly African American sample reported using PRC and NRC (assessed using the Religious Coping Activities Scale (RCA) [57]). They generally found that higher levels of PRC predicted less distress, whereas NRC, (i.e., feeling angry or distant toward God or members of the church), predicted greater distress. Overall, in a variety of studies, NRC consistently has been linked with adverse outcomes [58].

\subsection{Spiritual Struggle}

One's spirituality can be experienced as both a source of strength and a source of strain [42]. Pargament and his colleagues' [44] two-year longitudinal study ascertained that a crisis of faith was the clearest predictor of looming death in medically ill elderly patients, even when all other variables were controlled, indicating the gravity of this type of response to serious life stressors. Research shows that spirituality is not always supportive in terms of adapting to losses, even though distressed adults typically use more PRC than NRC [43,44]. In fact, loss can usher in spiritual distress [59], and is often conveyed by the griever in terms of anger toward God or in an inability to accept that a good God would allow a loved one to die [60], especially when the death is grotesque or gruesome. Unfortunately, research is sparse in relation to psychological outcomes for individuals whose usual forms of spiritual coping fail [14], especially when faced with the loss of a loved one to violent means.

Empirically what is known is that individuals who have suffered horrific violence, such as a loss through homicide, likely are more susceptible to feeling or expressing extreme anger toward God [61]. Edmondson and colleagues [24] argued that distressed people often experience religious struggle because they feel that they are at the mercy of a domineering yet unsympathetic God who lacks empathy, are being unfairly disciplined by Him or, perhaps worse yet, completely abandoned. Accordingly, because for many survivors spirituality goes hand in hand with grief, and because it may be particularly tested following violent death, it is critical for clinicians to develop a deeper appreciation for spiritual struggle and spiritual crisis in order to support these underserved populations.

\subsection{Spiritual Crisis Following Loss}

A multi-disciplinary team consisting of researchers [59] and a Pittsburgh church's bereavement response team conducted a pilot study to develop a church-based grief intervention which illustrated the role of loss in affecting a griever's spiritual well-being. Shear and her colleagues investigated grief reactions of 31 African American parishioners who, for the most part, were grieving the loss of a loved one to natural rather than violent means. In relation to the effects of the loss on the griever's faith, grievers responded to options ranging from "faith stronger than ever" to "faith seriously shaken". 
Congregants' self-reports revealed that $19 \%$ of the participants had experienced some degree of negative shift in their faith as a result of the loss. Shear and her colleagues interpreted these findings by asserting that spirituality plays a critical function for spiritually inclined individuals after the death of a loved one, such that they apparently not only experience the loss relationally in terms of the deceased, but also on a spiritual level where deaths are viewed as something arranged by God. The researchers maintained that experiencing grief in spiritual terms is similar to experiencing grief psychologically, where reactions to loss are viewed on a continuum of highly resilient to severely complicated responses, with the most problematic spiritual response being termed complicated spiritual grief (CSG) [59]. CSG has been conceptualized as a spiritual crisis in the mourner's relationship with God, such that he or she struggles to reestablish spiritual equilibrium following loss, often accompanied by a sense of discordance, conflict, and distance from God, and at times with members of one's spiritual community [59].

Although some mourners ultimately derive something positive from enduring a crisis of faith stemming from ongoing spiritual struggles due to a loss, others definitely do not. For some grievers whose constructs of God or the universe are contested, such as when adolescents are bereaved of their siblings, the survivor's faith often is shaken to its core. One spiritually distressed young teen exemplified this phenomenon by saying: "I don't really care now about sinning... It doesn't matter to me as much... since (my brother's death). I guess it is my way of getting back at God" ([60], p. 542).

As Hill and Pargament [25] aptly stated, for some distraught individuals, enduring a spiritual crisis constitutes the death of one's faith, per se.

\section{Complicated Spiritual Grief-A Program of Research}

Given both the dearth of research studies designed to assess spiritual crisis in the context of bereavement and our own findings from various samples and regions, we present below a program of research that explores the challenges in the lives of many individuals experiencing loss through the lens of their faith.

\subsection{Complicated Spiritual Grief and Complicated Grief Following Homicide Loss [26]}

Our examination of spiritual crisis following loss began in Memphis, TN, in a region where religion, spirituality, and faith occupy a place of prevalence, prominence, and honor, as we initially worked with a sample of individuals whose family member or friend had been murdered. Our original goal was to conduct an exploratory, two-assessment study with a sample of 46 African American homicidally bereaved individuals to measure distress levels in the wake of horrific circumstances of loss and to increase our understanding of how survivors of homicide cope when their loved ones are unexpectedly and violently taken from them. Although primarily in an attempt at thoroughness on our part in desiring to conduct a well-rounded inquiry, study participants completed a measure evaluating both spirituality as a resource and as a source of strain (Brief RCOPE) [46]. We did not set out to investigate spiritual struggle per se, nor did we anticipate seeing a breakdown of faith in this sample. Given that our sample was comprised entirely of African Americans, most of whom endorsed Christianity as their faith tradition, our pre-assessment assumptions were that their faith would instead serve as a bulwark during such debilitating times. 
In spite of this initial premise, we demonstrated, through a series of multivariate analyses exploring bereavement distress and spiritual crisis, that CSG is a serious, yet understudied, form of bereavement distress that can be found even among individuals who espouse high levels of faith as a means of coping with devastating life trials. Our longitudinal study revealed that not only did survivors demonstrate greater use of religious coping more generally than did individuals in other samples, such as distressed college students, Oklahoma City bombing survivors, medical inpatients [42], medically ill elderly [44], and dying patients [43], but also that their level of spiritual struggle (as assessed using the negative religious coping, NRC, scores on the Brief RCOPE) [42] was nearly twice as high in comparison. Additionally, we found that CG was associated with CSG at both Time 1 (T1, initial interview) and Time 2 (T2, 6-months later) and that PRC was uncorrelated with CG at either time point. Moreover, CG at T1 predicted CSG at T2, but the opposite did not hold true (CSG at T1 did not predict CG at T2). When examined on an item-by-item level, we found that T1 CG proved significant in predicting four out of seven items on the T2 NRC subscale - specifically in terms of the griever wondering what he/she did to receive God's punishment, questioning God's love, feeling abandoned by the church community, and questioning the power of God.

When we bifurcated our sample into survivors who screened positive for CG (complicated grievers; CGs) and those who did not (non-complicated grievers; NCGs), we found that CGs experienced higher levels of CSG than did non-CGs, but that there was no difference between the two groups in terms of PRC. When testing to see if specific CG symptoms at $\mathrm{T} 1 \mathrm{might}$ prospectively predict subsequent religious coping items, we found elevated mean scores on three items from the Inventory of Complicated Grief-Revised (ICG-R) [29] \#1 feeling devastated/overwhelmed by the death, \#5 longing/yearning for the deceased, and \#7 feeling angry about the death — in comparison to other items on the scale. Yet, only \#5, longing/yearning for the deceased, the theoretically central feature for diagnosis of CG [29], was statistically significant in prospectively predicting spiritual crisis, in terms of the griever's questioning what he/she did to receive God's punishment, questioning God's love, and feeling abandoned by the church community. Finally, in our sample, overall, levels of CSG decreased over time, but the rate of decrease in CSG scores for the CG group was substantially less than the rate of decrease for the non-CG group. For those individuals whose CSG scores increased, the CG group reflected a greater increase - a rate that was 56\% higher than the non-CG group.

Thus, we established a strong link between CG and subsequent spiritual crisis. In fact, our results substantiated that, in comparison to non-symptomatic grievers, individuals in our sample with high levels of both CG and CSG might need more than simply compassion and the passage of time in order to successfully adapt to traumatizing loss. Rather, specialized psychotherapy interventions targeting CSG symptoms are likely necessary for some grievers, especially for spiritually inclined survivors of violent death.

\subsection{Complicated Spiritual Grief, PTSD, and Depression [62]}

Logically, our next step was to conduct a follow-up study with the same sample of homicidally bereaved African American adults, examining the relation between psychological distress (in the form of CG, PTSD, and depression) and positive- and negative religious coping to establish if psychological distress more strongly predicted religious coping or vice versa in the same sample (46 African 
American homicide survivors). Although CG is a distinct and highly concerning form of bereavement outcome, we also recognized that PTSD and depression are worthy of attention in the context of homicide loss. Therefore, because the two forms of religious coping were differentially related to CG in our previous study [26], one goal of this research was to test to see if the same held true for PTSD and depression within the same sample.

Given that studies show that homicide is one of the most difficult types of loss to bear [8], and that the initial shock after the murder can be especially challenging, our findings that grievers bereaved for a shorter length of time prior to assessment also struggled more in terms of their grief, were not surprising. However, we anticipated that we would see more PRC and less CSG over time as that initial shock wore off. We saw, instead, no relation between time since loss (TSL) and religious coping. In fact, we found that the use of positive forms of religious coping showed essentially no relation to bereavement distress at either time point, which was consistent with our previous study [26]. And yet, this challenges the assumption that those survivors who rely more strongly on their faith will necessarily have better outcomes when faced with an atrocity such as the murder of a loved one, which could test even the most robust coping system. Conversely and more optimistically, our findings seem to indicate that religious mourners turn to their faith as a source of comfort and sense making even in the face of homicide, which helps explain the lack of correlation between constructive religious coping and grief at either time point, and is suggestive of the relative immunity of positive forms of faith from being destroyed by the trauma of violent death loss.

Studies that have followed the bereavement trajectories of spiritually inclined survivors indicate that grief can give way to a crisis of faith in some individuals [59]. Our previous work showcased the predictive nature of CG in a study using this sample of homicidally bereaved adults by determining the prospective risk that $\mathrm{CG}$ presents in terms of spiritual struggle in violently bereaved individuals [26]. Thus, not only did CG predict CSG in a general sense but it did so on an item-by-item level, as well. As a result, having previously established $\mathrm{CG}$ as a predictor of spiritual distress after the loss of a loved one to violent means, in this study we sought to determine whether the predictive power of CG in terms of NRC was beyond that of PTSD and depression. It was not surprising, however, given the association between our distress measures, that CSG was correlated with nearly every type of bereavement outcome at both time points. However, consistent with our hypotheses, our analyses revealed that in terms of prospectively predicting CSG, CG was the only significant predictor of post-loss spiritual distress in our sample. We interpreted from this that the agony over the griever's loss of relationship with the deceased is at the core of CG itself, and as such generalizes to a similar agony in relation to his/her relationship to God.

Our understanding of both CG and CSG has been amplified by our results showing that CG supersedes PTSD and depression as a prospective predictor of CSG. This is especially true in terms of treatment. As clinicians increase their awareness that spiritual distress in bereavement is directly related to the loss of the loved one, rather than to depressive or traumatic symptomatology, they will be better able to guide survivors as they seek to make sense of their loss $[37,45,46]$. For instance, when maladaptive grieving clearly necessitates therapeutic intervention [63], evidence-based therapies, such as those that promote a healthy continuing bond with the departed loved one by using narrative techniques such as imaginal conversations [64], could both attend to the separation distress in relation to the deceased and also establish a foundation for similar reestablishment of an ethereal connection 
with the divine. Nevertheless, more research is necessary to design interventions specifically tailored to meet the needs of highly distressed individuals suffering from both CG and CSG (see Future Directions below). In the case of violently bereaved individuals who appear to be especially predisposed to this often overlooked form of bereavement distress, such interventions likely would be especially pertinent.

\subsection{Complicated Spiritual Grief and Meaning Making in a Diverse Sample [65]}

In the foregoing research we demonstrated the link between CG and CSG in a sample of religious African Americans suffering a particularly traumatic bereavement. But what might we expect from a sampling of grievers who vary greatly in terms of ethnicity, church affiliation, and circumstances of the death? Additionally, what might we learn in terms of spiritually inclined grievers' ability to make sense of their loss in light of or in spite of their faith?

To explore these questions, we recruited a heterogeneous sample of 60 adults who were bereaved within the past 5 years and endorsed the Christian faith tradition. Type of loss was assessed as: natural anticipated (e.g., lengthy illness), natural sudden (e.g., heart attack), homicide, suicide, or fatal accident. Participants were recruited from: several large, local churches, Victims to Victory (VTV), a faith-based homicide agency that assists homicide survivors, and psychology undergraduate classes at a large, state university.

To maximize diversity in the sample with regard to ethnicity and type of loss, several large churches that serve (a) predominantly African American congregations; (b) primarily Caucasian congregations; and (c) multi-racial congregations were invited to participate, as well as clients served by VTV. Similar diversity was achieved in the college sample given the mixed-racial nature and size of the university student body as a whole.

Challenges to meaning making have been shown to exacerbate grief (e.g., [11]) and making sense of one's loss has been correlated with greater psychological health (e.g., [66]). Religious individuals who successfully construe their losses spiritually (i.e., who use religious coping strategies to make meaning) experience less grief concomitantly (e.g., [37]); and conversely, survivors who struggle with making meaning of their loss appear to be more susceptible to spiritual crisis (e.g., [26]). Thus, both meaning and spirituality have been individually associated with bereavement outcomes. However, less is known about the association between meaning made and specific types of religious coping. Therefore, the purpose of our next study was to determine the extent to which the use of a variety of religious coping strategies, which can be viewed as meaning-making processes, predicted the degree of meaning made, which can be conceptualized as integration of the loss of a loved one.

While a number of theorists and researchers have discussed the dynamic link between spirituality and finding meaning in the face of adversity, in this study, we examined the extent to which the use of specific types of religious coping strategies was related to having made meaning of a significant loss in a diverse sample of spiritual and religious individuals bereaved by a range of causes. As hypothesized, we found that CSG (as assessed using the NRC subscale of the Brief RCOPE) [42] was significantly associated with difficulty making meaning of the loss of a loved one. In other words, those participants who experienced more spiritual and interpersonal religious discontent and who engaged in more negative reappraisals of God and God's power were challenged in their ability to make meaning of 
their loss. Given the cross-sectional nature of this study, it may also be, however, that individuals experiencing more challenges with the meaning-making process developed a sense of discontent with God and their religion because of their very difficulty with making sense of or finding a greater significance of their painful experience. Likewise, given the relatively small amount of variance explained by CSG in predicting meaning made $(6 \%)$, several other important factors likely contribute to challenges in meaning making.

Higher CSG scores reflected anger toward and a sense of distance from God and questioning one's beliefs/faith. Because individuals with strong religious beliefs use their existing global belief system to make meaning, it is not surprising that a compromised faith would predict difficulties comprehending how or why a significant interpersonal loss occurred and integrating the event into one's life. Marrone [67] highlighted the tendency that spiritual and religious individuals have to assimilate a significant loss into existing cognitive schemas that reflect their strong religious/spiritual beliefs and faith. He noted that individuals attempt to minimize threat to these assumptive beliefs, but when these cognitive structures are already compromised through a crisis of faith, meaning making is much more difficult [67]. In fact, individuals who reported discontent in our sample may have been in the process of accommodation, or major revision of their assumptive worlds, to assist them in making sense of why the loss occurred. The associations between meaning made and CSG in our study substantiate the position that the beliefs and experiences assessed by the NRC subscale, such as feeling spiritually abandoned, punished, or angry; questioning one's faith; and coming to distressing conclusions about why the event occurred (i.e., the devil made this happen); may represent an unsuccessful attempt to search for spiritual meaning, rather than negative religious coping per se. In other words, these Brief RCOPE items do not appear to reflect coping efforts or behaviors. Instead, researchers and theorists have begun to consider NRC to reflect spiritual struggles $[68,69]$. Individuals experiencing spiritual struggles may attempt to understand their loss using their spiritual belief system, but may find it yields an unsatisfactory sense of meaning and/or a resultant maladaptive narrative.

Additionally, grievers in this sample struggled with a crisis of faith that was associated with exacerbated grief reactions. Not surprisingly, in other studies spiritual struggles have been linked to increased psychopathology, including anxiety and depression [69], consistent with our finding linking spiritual struggles with $\mathrm{CG}$ symptoms. It may be that individuals begin to struggle with their spirituality because they are suffering from pathological levels of psychological symptoms, or alternatively, the spiritual struggles interfere with coping processes and lead to maladaptive cognitions and behaviors that in turn lead to the development of pathological symptoms. Our exploratory analyses suggested that difficulties with meaning making partially mediated the relationship between spiritual struggles and CG symptoms. Participants with lower levels of prolonged grief may have successfully applied non-spiritual meaning systems (e.g., concluding that death is a natural part of life, that the death concluded a life well lived) to assist them with integrating the death, though not in a specifically spiritual fashion. Having made meaning of the loss may in fact buffer against similar "meaning-related" symptoms of CG, such as challenges to one's sense of self (i.e., role confusion) and feeling that life is empty or meaningless since the death. The finding that challenges with meaning making predicted CG symptoms to a greater extent than spiritual struggles suggests the relevance of this sort of secular meaning making, even among more religious grievers. 
While our findings are exploratory and based on cross-sectional data, which limits our interpretation of the direction of causality between the variables examined, prior studies have demonstrated that meaning made is an underlying mechanism explaining the associations of various risk and protective factors with CG symptoms. Currier, Holland, and Neimeyer [11] found evidence that the degree to which one made sense of a loss nearly perfectly mediated the relationship experiencing a sudden, violent loss and CG symptoms. In this study, although meaning made partially explained the influence of CSG on CG symptoms, CSG still independently predicted CG symptoms. Because of the cross-sectional design of the study, we cannot determine whether in fact it is the underlying psychopathology that contributes to the struggle with spirituality and to the difficulties creating meaning. Furthermore, there may be another variable that causes both CSG and meaning made that was not examined in this study. Most likely, the relationships are complex and circular.

Contrary to our hypothesis, PRC was unrelated to the extent to which meaning was made. This finding appears counterintuitive, as one would expect PRC to facilitate meaning making; however, associations between PRC and adjustment have been mixed across studies [15]. Because our cohort was largely strongly religious, the benefits of PRC might have been masked and might be more easily detected in a sample with more variable degrees of religious involvement. Still, this explanation alone is insufficient, as CSG scores in our sample were equally skewed, and yet were robust in their association with difficulty making meaning of the loss. Notably, our results are congruent with our previous findings [26], where we observed that CSG but not PRC was associated with CG; and, similarly, that PRC was not associated with PTSD or depression [62].

Another explanation for the null findings may be because of the challenges of simultaneously engaging in religious coping efforts and meaning-making processes shortly after the loss of a loved one. It may be that the impact of PRC on meaning-making processes may increase over time, resulting in better outcomes as time passes. To explore this hypothesis, we conducted post hoc analyses, examining subgroups that were less than or equal to one year post-loss, one to two years post-loss, two to three years post-loss, and three to five years post-loss, in order to determine whether a significant association between PRC and meaning made occurred as time from the loss passed. This hypothesis was not supported, as all test statistics were non-significant $(p s>0.10)$. There was similarly no relation between PRC and CG symptoms for any of these subgroups ( $p \mathrm{~s}>0.10)$. To explore whether PRC was related to meaning made or $\mathrm{CG}$ in other subgroups, we also conducted post hoc analyses of the associations separately in violently and non-violently bereaved individuals as well as those with different relationships to the deceased (parent, spouse/partner, adult child, sibling/other relations). PRC likewise did not predict meaning made or CG symptoms in any of these subgroups ( $p \mathrm{~s}>0.10)$.

A final explanation of the absence of a significant association between PRC and meaning made or grief symptoms involves considering how individuals are using their positive spiritual beliefs. For some, it may indirectly result in avoidance that may impede the emotional processing and contemplation necessary for cognitive assimilation and integration of the loss into one's life narrative [67]. For others, redirecting one's attention away from the loss and toward other spiritual resources may help an individual to create meaning - helping to facilitate cognitive assimilation by reinforcing existing assumptions about one's faith. The varying effects of PRC may explain the absence of a linear association between PRC and meaning made. 
Our examination of the associations between various background variables and meaning made revealed that individuals who lost a loved one who was younger had significantly more difficulty with meaning making, likely reflecting the challenges of making sense of an untimely loss. Similar to prior studies, we found that individuals bereaved by violent causes had more difficulty finding meaning in their loss than those bereaved by non-violent, natural causes (e.g., [11]). Being present when the deceased was found also was related to more challenges with meaning making, which may be because having a visual image results in trauma symptoms (e.g., re-experiencing, avoidance) that lead to difficulty engaging in the confrontational work necessary for meaning-making processes. Also at heightened risk for challenges with meaning making in this sample were parents and spouses, which is likewise consistent with other studies (e.g., [37]) as well as the tendency for these groups to be at increased risk for a complicated bereavement [39]. Interestingly, however, other demographic factors were not significant in predicting meaning making when included in multivariable analyses. For example, we found no differences in how African American and Caucasian individuals, or married versus unmarried grievers processed their loss in terms of meaning making.

\subsection{Complicated Spiritual Grief and Complicated Grief: Comparing Violent vs. Non-Violent} Death Loss [70]

Relatively little research has been conducted on the conjunction of CG and CSG, generally, or in the lives of individuals bereaved by violent causes, specifically. Therefore, we sought to sample a group of mourners who by dent of their dissimilarities likely would provide a comparison from which to examine these constructs in the context of loss more generally. Thus, we collected data from several samples of bereaved adults who were diverse in terms of ethnicity, type of loss, and church affiliation, and who met the following inclusion criteria: 18 years old or older, endorsement of the Christian faith tradition, bereaved within the past 10 years (with a mean post-loss duration of $3 \frac{1}{2}$ years; $M=40.6$ months; $S D=2.6$ months), as CG is by definition a long-term condition whose outer bounds are still being established. We recruited a total of 150 bereaved individuals from community collaborators that included: (a) several large, local churches $(n=75 ; 50 \%)$; (b) Victims to Victory $(n=9 ; 6 \%)$; as well as (c) psychology undergraduate classes at a large, mid-South, state university $(n=66 ; 44 \%)$.

Consistent with previous studies [26,62,65], we found that two forms of spiritual responses, PRC and $\mathrm{CSG}$ - one characteristically considered positive and one negative - related quite differently to bereavement outcome. On the one hand, in this study, use of religion as a positive resource in coping proved unrelated to adjustment to loss, whereas maladaptive religious coping was consistently related to elevated grief, replicating our previous findings [26] with a sample of homicide survivors. This suggests that across multiple studies, PRC is unrelated to loss accommodation, whereas CSG is most problematic for individuals who have lost a loved one to violent means. Viewed from one perspective, this could suggest that attempting to cope with loss through positive recourse to one's religious beliefs does little to blunt the sharp pain of grief. However, the lack of correlation of these two variables could as legitimately suggest that mourners may continue to reach out to God and members of the faith community in constructive ways regardless of the intensity of their distress. In contrast, those who suffer bereavement complication appear to be at risk for spiritual distress. 
We have consistently found (see also [26]) that CG predicts CSG both globally (i.e., using NRC subscale scores [42] and Discontent total scores from the RCA [57]) and at an item-by-item level, even when correlated background variables are held constant. In fact, in the present study, collecting data on a larger, more diverse sample produced a greater number of examples, and a more heterogeneous model of spiritual struggle. Specifically, in addition to replicating previous findings [26], we found that grievers who struggled with the loss of their loved one also simultaneously struggled with feeling angry with or distant from God and from members of their church, felt punished by God for a lack of devotion, wondered whether God had abandoned them, questioned their religious beliefs and faith, and endorsed the notion that the devil made the death occur. However, unlike our homicide survivor sample [26], grievers in the present study with high levels of longing and yearning for their deceased loved one did not have high levels of CSG. In light of these findings, further analyses of these constructs comparing differences between violent and non-violent cohorts might illuminate nuances in grievers' experiences.

In relation to cause of death (i.e., natural death, such as a lengthy illness or a heart attack vs. violent death, such as homicide, suicide, or fatal accident), our findings revealed that this factor differentially predicted struggles with both grief and faith. Not surprisingly, mourners whose loved ones died violently reported the greatest difficulty accommodating the loss emotionally and spiritually. Specifically, those persons whose loved ones had taken their own lives, been murdered, or suffered a fatal accident experienced significantly greater complicated grief than did those bereaved by natural death. However, no differences were found between types of violent death losses on measures of spiritual struggle, suggesting that it may be their common elements, such as their suddenness, traumatic nature, or the role of human intention or inattention that can lead some believers to question their faith in light of the unpredictable, uncontrollable randomness of life. Thus, future research would do well to identify features of tragic losses that pose particular challenges to people's spiritual coping, particularly those subject to modification in applied contexts.

Clinically, our findings suggested the need for spiritually sensitive clinicians and clergy to work together to develop informed and culturally appropriate interventions for spiritually inclined bereaved clients, and especially for those whose losses are sudden, unexpected, and violent. More work is also warranted in the assessment of spiritual struggle in the specific context of bereavement, inasmuch as the existential issues that can arise in the wake of a loved one's death may differ in kind as well as degree from those triggered by less permanent or pervasive life stressors or transitions. The refinement of both assessment and intervention is likely to benefit from systematic qualitative research on the experience of spiritual struggle in bereavement, to yield a richer depiction of the distinctive themes that define such mourners' challenged beliefs, relationship with God, and connection to the faith community. Thus, we made a step in this direction through our companion study reported below [71].

\subsection{Complicated Spiritual Grief: A Deductive Inquiry Following the Loss of a Loved One [71]}

Despite an increasing body of quantitative research reviewed above, a gap in the literature existed in terms of close qualitative investigation of spiritual struggle following loss. Thus, using 84 participants' written responses to open-ended questions along with systematic exploration of this topic with a five-member focus group, we designed this qualitative study to better understand the firsthand 
experiences of bereaved individuals who have suffered a crisis of faith after the death of a loved one. To our knowledge, our study with a diverse sample of mourners represents one of the first attempts to report the narrative responses of individuals who suffer from CSG.

Our qualitative inquiry assisted us in obtaining a rich description of the construct of spiritual struggle in grief. To develop the focus group protocol, and participant eligibility, we analyzed data from 84 individuals (complete protocol details are outlined in our companion study above [70]) who had participated in the assessment sessions. We used a four-item, open-ended questionnaire to encourage participants to think about how they felt during the times when they struggled most deeply with the loss of their loved one and, specifically, to describe how the loss challenged their relationship with God and their faith community:

(1) What feelings or thoughts about God or your relationship with Him did you have following the loss of your loved one?

(2) Please discuss the ways in which the loss strengthened or challenged your relationship with God.

(3) What feelings or thoughts about your faith community or your relationship with it did you have following the loss of your loved one?

(4) Please discuss the ways in which the loss strengthened or challenged your relationship with your faith community.

Consistent with prior research [19] we found that spiritual struggle was a fairly common experience among church-goers in our study. Overall, 36 out of 84 participants (43\%) endorsed CSG on the qualitative questionnaire. Of these, 20 out of 36 participants (56\%) endorsed CSG at least once in relation to both God and their spiritual community, and 10 out of $36(26 \%)$ participants endorsed CSG in at least 3 of 4 questions. Nine out of 84 individuals (11\%) endorsed CSG on both qualitative and quantitative assessments (see [70]).

In relation to the qualitative assessment of CSG, we developed an a priori coding scheme to analyze and report key concepts in the questionnaire narratives. We used directed content analysisthe deductive use of existing theory or prior research to better understand a previously explored phenomenon and establish key concepts or variables as initial coding categories [72] - to "validate or extend conceptually a theoretical framework" ([73], p. 1281). Specifically, we referred to quantitative items representing spiritual distress found on measures used in this study (i.e., the NRC subscale of the Brief RCOPE [42] and Discontent subscale of the RCA [57]; see [70]) to determine the presence of spiritual crisis in the participant's responses. We used quantitative items as our criteria to guide decision making. Thus, we highlighted and coded text from participants whose narrative on the open-ended questionnaire broadly reflected spiritual crisis based on our analytical criteria. These individuals were eligible to participate in the subsequent focus group session.

We initially identified 15 potential focus group members based on their endorsement of CSG from quantitative scales and their narrative responses to the qualitative questionnaire indicating high levels of spiritual crisis. Of 15 invited participants, five individuals gave phone consent to participate in a focus group lasting approximately $60 \mathrm{~min}$. Based on Mayring's [74] method of deductive category application, we used our quantitative and qualitative findings to inform our semi-structured focus group questions and to aid in creating a coding scheme. Thus, we inquired about focus group members' loss-related spiritual experiences, questioned if our findings about spiritual crisis in 
bereavement resonated with them, and invited them to share what had helped them or what they believed might help others. These tape-recorded discussions were then transcribed and analyzed using our coding scheme.

Our results revealed that as a result of the loss, focus group members' overarching narrative was one of resentment and doubt toward God, dissatisfaction with the spiritual support received, and substantial changes in their spiritual beliefs and behaviors. Within this narrative of loss, 17 specific themes emerged relative to CSG. The most common themes (i.e., those that emerged repeatedly in the data of multiple participants; $n=6$ ) and the salient themes (i.e., concepts or experiences that were striking or unexpected; $n=11$ ), along with subthemes, are outlined below.

The six most common themes included:

(1) Questioning God's Character. A weakened faith in God following loss can cause one to question God's character-his goodness, caring, intentions, and reasoning.

(2) Negative Feelings toward God. Negative perceptions and feelings in relation to God often emerge in the form of anger and confusion, leaving the griever devastated and shocked.

(3) Lack of Spiritual Sense Making. Some bereaved individuals struggle to make spiritual sense of their loss, often because their constructs or assumptions about God or life have been shattered as a result.

(4) Misunderstood by Spiritual Community. Well-intentioned yet fallible support can cause grievers to feel misunderstood by their spiritual community, especially when would-be supporters respond to their grief with invalidating clichés or questions.

(5) Negative Feelings about Spiritual Community. Spiritually inclined grievers can have negative perceptions and feelings in relation to the spiritual community, specifically when they feel judged or condemned for being angry at or questioning God following their loss.

(6) Selective about Sharing Feelings. Overall, mourners expressed a sense of frustration with the support received from their fellow church members, leaving them reluctant to show their true feelings because they feared receiving still greater hurt as a result.

Beyond the themes that commonly were endorsed by most members of the focus group over the course of the interview, a number of other less common, yet salient themes were striking and unexpected because of the level of distress and degree of passion expressed. These included:

(1) Spiritual Crisis Coupled with Strong Faith. A weakened faith in God that eventuates in a spiritual crisis also can be coupled with a strong faith that is not always realized or appreciated by one's spiritual community.

(2) Betrayed and Robbed. Betrayal, and a sense of feeling robbed following loss are sometimes related to grievers feeling that their spiritual community lied to them about God's character.

(3) Questioning What They Did to Cause Death. For some bereaved individuals, spiritual crisis is tied to a questioning of what they or their deceased loved one did to cause or deserve death.

(4) Desire to Hurt God in Return. Feelings of intense anger and cursing at God are sometimes exhibited by the griever as an attempt to hurt God in return for the pain he or she attributes to Him.

(5) Abandoned by Spiritual Community. Distrust in the form of questioning their spiritual community's beliefs and intentions, and feelings of emotional or physical abandonment or 
neglect by the spiritual community caused some individuals to go to a new church where they could be anonymous.

(6) Silent Silencers. Bereaved individuals criticized their spiritual supporters who they felt remained silent about the death (as if had not happened), placed unrealistic expectations on them, would not let the griever express how he/she felt, tried to convince the griever to think differently, viewed the griever as a victim only, or appeared more concerned about their own comfort than the griever's pain.

(7) Avoided Spiritual Community. Some grievers avoided their spiritual community in part because they questioned their community's ability to handle their grief or because they feared that their own painful feelings would not be well received.

(8) Understanding Not Pity. Spiritually inclined grievers expressly stated that they do not want pity from their spiritual community, but do need them to try to understand how they feel.

(9) Faith-Related Changes. Changes in the griever's faith-related behaviors, activities, and attitudes were expressed in terms of lower levels of church volunteerism, allowing his or her mood to govern levels of participation, or choosing to no longer worship God or fellowship with others at all, choosing not to celebrate religious holidays, and an overall sense of being less faithful.

(10) Afterlife Concerns. Concerns related to the afterlife were reflective of spiritual crisis. Specifically, grievers wondered about their loved one's destiny or if they would see him/her again, and questioned the existence of heaven and hell.

(11) Lapse of Faith. Spiritual crisis that culminates in the bereaved individual walking away from God may represent a temporary or permanent loss of faith-a composite of both overt struggle (e.g., that the person is weak, lacks faith, has a poor knowledge of God or his Word) and hidden strength (e.g., the spiritual crisis might fluctuate, or might not last forever).

Specifically, focus group narratives highlighted themes of loss-related spiritual distress and abandonment. For example, Rhonda told how her dad felt "emotionally neglected" by their church leaders following the loss of her mother. In her words: "We made a large need known. You know, it wasn't like they didn't know. We made it clear. However, they chose not to [help]." Conversely, Caroline explained how she left her congregation before church members could outright abandon her. "I just took myself out of ... the whole situation. I guess I abandoned them first."

Responses revealed that although violent death loss predisposed survivors to subsequent spiritual distress, even survivors of natural deaths sometimes suffered a crisis of faith. Results revealed that spiritually inclined grievers who struggled with their faith felt a myriad of emotions relative to God and their faith community. In relation to God, the focus group's feelings can be summed up in terms of spiritual anguish - a sense of traumatization at the ways in which their spiritual lives were devastated by the loss, leaving a residual sense of anger and bewilderment in relation to God. Absorbing such inexplicable pain caused some in our sample to curse God as a way of getting back at him. Conversely, yet consistent with our quantitative findings [70], bereaved individuals who struggled spiritually following loss often did so because they felt punished - as if they or their deceased loved one did something that warranted death. Finally, for some, the death elicited significant distress about their loved one's final resting place and an invalidation of core assumptions about the hereafter. 
In terms of the faith community, focus group members reported feeling misunderstood, primarily when spiritually like-minded supporters responded to their grief with invalidating platitudes, truisms, and banalities. Additionally, they recalled a sense of condemnation and judgment from the very people they looked to for support following a difficult loss. It seems, however, that negative feedback from would-be spiritual supporters was accentuated when grievers admitted to being angry at God or having questioned God about the death of their loved one. However, a sense of frustration with the support received seemingly made some focus group contributors more guarded. For instance, a recurrent theme was that substantial discernment was in order when it came to what and with whom grievers would share in terms of their true feelings, primarily out of anticipation that to not differentiate could exacerbate rather than alleviate their psycho-spiritual pain.

Strong emotions surfaced as a result of our questioning. For example, bereaved individuals whose spiritual relationship with their church was in a state of crisis passionately expressed that they felt betrayed, robbed, and lied to. On top of their grief, some reported that mourning was more burdensome and spiritually painful when fellow believers' claims about God's goodness, intention, and reasoning did not mesh with their lived experience. Scrutinizing the spiritual community's beliefs, attitudes, and motives left grievers feeling neglected and fostered a sense of abandonment. Thus, a surprising number of congregants in our study reported that they responded to these experiences by making a fresh start and seeking safety and anonymity in a new church.

Relational avoidance of the spiritual community by the griever was an unanticipated theme arising from our analyses. Participants in the focus group reported that they often avoided fellow church members, primarily because they doubted whether the average congregant would hear their pain or could handle their grief. Thus, to the survivor, avoiding the topic altogether seemed like the only viable option. Frequently, participants characterized fellow congregants as what we have termed silent silencers. On one hand, some in their spiritual support network did not want to acknowledge that the death had occurred or that they were grieving. On the other hand, it was also made clear that something about the way they were expressing their grief was not acceptable. A poignant example came from Suzanne, who lost her grandmother unexpectedly:

"At first, a lot of people didn't know what had happened and so when they did, the sense I got from them was, 'You know, please don't erupt into tears.' When I got to the point where I was sharing a little bit more, I could tell they were like, 'I would've been satisfied with just a 'fine'. Don't keep going.' Like, they didn't really want to know. You know, when you ask someone how they're doing, you need to be prepared that they're not going to say 'okay'." But it was clear that [that was not what they wanted to hear]."

Overall, focus group members conveyed that their supporters seemed to place more emphasis on their own comfort and wellbeing than on that of the mourner. In their defense, supporters who feel helpless often ask grief experts, "So, how can I help? What should I say to someone who is struggling with a loss?" The answers call for creativity on the part of spiritual leaders as they educate their parishioners, especially when juxtaposed with our finding that spiritually inclined grievers do not want to be felt sorry for but, instead, crave like-minded others who try to understand their pain.

In our sample, when both the reality and finality of loss threatened a griever's core constructs, his or her assumptions about God and life were likewise decimated. Thus, a desperate yet unsuccessful attempt to make sense of the loss in spiritual terms ensued. Not surprisingly, such spiritual discontent 
was often mirrored in changes in the bereaved individual's faith-related behaviors, activities, attitudes, and beliefs. In terms of beliefs, perhaps some of the most concerning are those that involve eternal destiny. Faced with bereavement-related spiritual crisis, even people with a strong belief system sometimes find themselves questioning foundational doctrines such as heaven, hell, and their loved one's eternal salvation.

An unexpected finding was that a spiritual crisis does not necessarily indicate weak or immature faith. Rather, the participants conveyed that, although rarely acknowledged or respected by the religious community, even people with a solid faith in God can struggle tremendously, especially when facing life without a treasured attachment figure. Moreover, even individuals who feel that they can no longer participate in organized religion or maintain a relationship with God might return to both again at a later date, perhaps once the pain of the loss has lessened.

Finally, although all focus group participants endorsed CSG in their questionnaire narratives and during the group session, not all of them endorsed high levels of $\mathrm{CG}(n=3$; as assessed using the ICG-R [29]), or high levels of CSG quantitatively ( $n=3$; as assessed using the NRC [42] or Discontent subscales [57]). This highlights the advantage of a study that includes an open-ended questionnaire and a focus group, which enabled us to capture qualitatively what we could not quantitatively.

\subsection{The Inventory of Complicated Spiritual Grief (ICSG) [75]}

Evaluation of poor bereavement outcome in the form of religious/spiritual distress has been understudied to date. However, the dearth of studies examining this phenomenon likely is in part due to researchers having inadequate means with which to do so. As we have outlined below, the few available scales measuring psycho-spiritual pathology have only in rare cases been tested with grievers' data and none, to our knowledge, were specifically designed for use with individuals experiencing the loss of a loved one. Therefore, we were compelled to develop and test a measure of complicated spiritual grief to bridge this critical gap.

Spiritual crisis often is assessed in terms of negative emotions, attitudes, and behaviors related to God, and sometimes in terms of one's spiritual community. Some studies of the construct have used only single items (e.g., [76,77]), while others have used event-specific scales (e.g., [77]) or subscales derived using factor analysis (e.g., [78]) to assess this construct. Other studies have assessed both supportive spirituality (e.g., positive religious coping; PRC) and spiritual struggle (e.g., NRC; Brief RCOPE [42]; see also the Spiritual Assessment Inventory or SAI [79]; Attitudes Toward God Scale-9 or ATGS-9 [80]). These measures, while useful, dedicate only a few items to assessment of spiritual struggle. Although Exline and Martin [61] found a parsing of such subscales to be informative in their exploration of disappointment and anger at God, we posited that the development of a dedicated measure of spiritual crisis in bereavement could advance research by permitting a psychometrically sound assessment of such struggle. Furthermore, developing a measure of various aspects of spiritual struggle, such as doubt and resentment toward God, dissatisfaction with religious activities and fellowship, and substantial changes in the griever's spiritual beliefs and behaviors following the loved one's death (see also [75]), could promote more nuanced understanding of the experience that might prove clinically useful, as well. Our measure, entitled the Inventory of Complicated Spiritual Grief (ICSG) pursues a more fine-grained inquiry of spiritual crisis (e.g., I don't feel very much like joining 
in fellowship to praise God or to glorify Him; or I sense the absence of God more than I do the presence of $\mathrm{God}$ ) compared to the more generic assessment of, for instance, the SAI (e.g., There are times when I feel betrayed by God; [79]), the Brief RCOPE (e.g., Felt abandoned by God [42]), or the ATGS-9 (e.g., Felt angry at God [80]).

Our goal was to develop a measure of spiritual crisis in bereavement (i.e., the ICSG), and to evaluate its specific application to bereaved samples (see Appendix for a full version of the measure). To do so, we collected data from a diverse community sample of 152 bereaved individuals and a comparable number of bereaved students in psychology undergraduate classes at a large, mid-South, state university. Our results established the psychometric properties of the 18-item instrument, including its two subscales-Insecurity with God and Disruption in Religious Practice. Exploratory factor analysis with the community sample supported this two-factor solution assessing (a) feeling angry, confused or unprotected by God following the loss; and (b) withdrawal from worship and other religious practices as well as the mourner's spiritual community. Replication with the student sample using confirmatory factor analysis further evidenced the generalizability of this model. Overall, the ICSG performed well in terms of the internal consistency and high test-retest reliability of both subscales as well as the total ICSG.

Consistent with previous studies linking CSG with CG [26,62,70] our findings revealed that bereaved individuals in our sample who scored highly on general measures of spiritual struggle and who were highly distressed over the loss of their loved one likewise scored high on the ICSG. Interesting patterns also emerged from analyses of both samples in terms of associations between ICSG subscales and other measures used to test convergent validity. Specifically, spiritually inclined grievers who were more displeased, disappointed, and felt less supported by God had more difficulty making sense of the loss and experienced more grief-related distress, whereas those who, as a result of the loss, reported more disruptions in religious participation at both an individual level and with their spiritual community engaged in fewer positive religious activities, performed fewer good deeds, and endorsed greater levels of religious avoidance in relation to their loss.

Specific demographic factors also were associated with participants' ICSG scores. For example, Caucasian mourners in both groups endorsed greater disruption in terms of their religious activities than individuals of other ethnicities. Likewise, questioning God's intentions or attentiveness in relation to their loss was endorsed more frequently by bereaved Caucasian students than by other groups (primarily African Americans) in both cohorts in our sample. Perhaps these findings are a reflection of the overall higher endorsement of spiritual engagement by African Americans [16]; although our study with violently bereaved adults found that African Americans seemingly endorsed high levels of both PRC and NRC compared to other samples of distressed individuals [25].

Although type of kinship to the deceased (e.g., spouse, parent, child) did not differentially predict spiritual crisis in our community sample, college students who lost a member of their immediate family reported greater spiritual distress than did students who lost a more distant family member (e.g., uncle, grandparent). In a large college student sample, Laurie and Neimeyer [81] also found that young adults who lost a closer versus a distant family member or friend reported greater grief. Additionally, in our community sample, violent death loss (i.e., accident, suicide, or homicide) was associated with greater distress in the griever's relationship with God, and with greater interference 
with the griever's religious practices and fellowship across both samples. These results substantiate our previous studies with African American homicide survivors [26].

Compared to previous measures, the ICSG is unique in offering a multifaceted measure of spiritual crisis using a wide array of statements representative of anger and distrust toward God, as well as disruptions in the bereaved individual's post-loss spiritual practices and fellowship with the spiritual community. Notably, our incremental validity analyses supported the uniqueness of this new assessment tool, with ICSG scores being uniquely associated with more severe complicated grief reactions, even after controlling for scores from a more generic measure of spiritual struggle. Interestingly, the empirical structure of the scale seems to bear on the time-honored distinction between a "vertical" dimension of religiosity in relation to the divine, and a "horizontal" dimension bearing on the individual's relationship to the faith community [82]. The present results suggest that both may be significantly challenged by the death of a loved one, potentially compounding the losses associated with the death itself.

The ICSG therefore comprehensively evaluated CSG using numerous candidate items bearing on such reactions, beyond the more generic measures of spiritual struggle included in currently available scales such as the SAI [80], the Brief RCOPE [42] or the ATGS-9 [80], all of which were tested with non-bereaved samples of adults experiencing a wide array of negative life events. In keeping with the intent to develop a measure uniquely relevant to bereavement, we found that the ICSG had "incremental validity" in predicting grief outcomes even after scores on general "negative religious coping" were taken into account. Thus, in developing the current measure in the specific context of bereavement and pursuing its validation using two diverse samples of bereaved adults, our goal was to shed additional light on mourners' spiritually inflected struggles to find meaning in loss [83] as well as to "gain comfort and closeness to God and others during times of frightening vulnerability" ([26], p. 304).

\section{Future Directions}

\subsection{Spiritual Meaning Making in Family Members of Terminally Ill Veterans [84]}

Given the established link between CG and CSG [26,62,70] and because meaning making has been linked to a crisis of faith specific to the mourning period [65], we have expanded our inquiry to underserved populations. Specifically, we found in Veteran samples that the role of faith and meaning making has received far less attention in terms of providing an explanation about why some survivors fare better than others, both in terms of grief, more generally, and CSG, specifically. Thus, we currently are conducting a longitudinal, three-assessment study designed to explore risk factors of CG in 60 survivors of hospice-eligible, terminally ill Veterans and to evaluate the role of spiritual crisis and meaning making in terms of bereavement outcome.

\subsection{Spiritual Adaptation to Loss: A Pilot Intervention for Spiritually Inclined Grievers [85]}

Our current and past studies highlighting the prevalence and problems stemming from a crisis of faith following the loss of a loved one accentuates the need for equally thoughtful interventions to ameliorate spiritual distress. Thus, we are currently collaborating with Michelle Pearce and Debra Wiegand of the University of Maryland, Baltimore, who have designed a novel intervention specifically 
for spiritually inclined individuals and are testing it with family members of patients who die while being treated in a major medical center. The treatment consists of bereavement-specific, directed writing disclosure exercises that facilitate participants' self-defined religious/spiritual perspectives of the bereavement experience, and is compared to grievers who write about their deepest thoughts and emotions related to the loss using a non-directed emotional format, and to a control group who write about the room's surroundings. Participants' writing samples will be analyzed in relation to bereavement-related outcome measures to test our hypotheses that over time bereaved individuals receiving the intervention will have decreased symptoms of CSG, CG, and depression, and a greater ability to make sense of their loss, improved physical health, and signs of post-traumatic growth. In sum, this study will test an innovative grief intervention to assist bereaved individuals with the goal of reducing distress related to their loved one's end of life and facilitating a positive adaptation to their loss. We anticipate that it will be helpful to nurses, chaplains, and palliative care teams as they offer additional support and spiritual care to bereaved family members.

\section{Conclusions}

The link between a crisis of faith and overall poor bereavement outcome cannot be ignored without doing a disservice to many religiously inclined mourners. Informative studies of the prevalence and levels of maladaptive spiritual coping are only just now emerging, and hence to date have been conducted with only a handful of samples. Likewise, assessment tools and psychotherapy techniques suitably designed to measure and alleviate psycho-spiritual anguish are overdue in both research and clinical settings. It is for these reasons we have concentrated on empirical exploration of these constructs and how, when, and why they intersect. We hope that follow-up studies, preferably with varied samples - including samples professing other religious orientations beyond Christianity — will benefit from the initial efforts outlined above as a springboard for increased understanding as to the nuanced aspects of the role of faith in, at times, exacerbating the grief process.

\section{Acknowledgements}

This work was supported in part by the Tennessee Board of Regents for the projects African Americans in Bereavement: Longitudinal Responses to Traumatic Loss, and African Americans in Bereavement II: Assessment and Treatment of Complicated Spiritual Grief following Traumatic Loss. The authors gratefully acknowledge this support, as well as that of Victims to Victory, and the invaluable assistance of Mae-Lynn Germany.

\section{Author Contributions}

Laurie A. Burke spearheaded the research program on which this article is based, and took the lead in writing most of the text of the current manuscript. She continues to pursue research in spiritual adaptation to loss, both in the context of bereavement and in end-of-life care, such as response to a loved one's palliative care experience. The assessment of spiritual struggle remains a focus of her research, and she currently is refining measures of this construct. Robert A. Neimeyer, served in a supportive role in many of the studies reported in this article, and shared responsibility for its 
composition, particularly in sections concerned with meaning making and the clinical implications of this research. He and his colleagues are actively pursuing research on predictors of complicated grief and are devising and validating interventions that focus on the search for significance in the wake of loss.

\section{Abbreviations}

CG: complicated grief;

PGD: prolonged grief disorder;

MDD: major depressive disorder;

PTSD: posttraumatic stress disorder;

PRC: positive religious coping;

NRC: negative religious coping;

CSG: complicated spiritual grief:

CGs: complicated grievers;

NCGs: non-complicated grievers;

T1: Time 1;

T2: Time 2;

VTV: Victims to Victory;

TSL: time since loss.

\section{Appendix}

Inventory of Complicated Spiritual Grief (ICSG)

Please think about your loss of , and then read each statement carefully. Choose the answer that best describes how you have been feeling during the past 2 weeks including today. Please answer these based on how you actually feel, rather than what you believe you should feel.

Table A1. Inventory of Complicated Spiritual Grief (ICSG).

\begin{tabular}{|c|c|c|c|c|c|}
\hline Items & $\begin{array}{l}\text { Not at } \\
\text { all true }\end{array}$ & $\begin{array}{c}\text { A little } \\
\text { true }\end{array}$ & $\begin{array}{l}\text { Somewhat } \\
\text { true }\end{array}$ & $\begin{array}{c}\text { Mostly } \\
\text { True }\end{array}$ & $\begin{array}{c}\text { Very } \\
\text { definitely } \\
\text { true } \\
\end{array}$ \\
\hline (1) I don't understand why God has made it so hard for me. & 0 & 1 & 2 & 3 & 4 \\
\hline (2) I have withdrawn from my fellowship with other believers. & 0 & 1 & 2 & 3 & 4 \\
\hline $\begin{array}{l}\text { (3) I go out of my way to avoid spiritual/religious activities } \\
\text { (e.g., prayer, worship, Bible reading). }\end{array}$ & 0 & 1 & 2 & 3 & 4 \\
\hline (4) I no longer feel safe and protected by God. & 0 & 1 & 2 & 3 & 4 \\
\hline $\begin{array}{l}\text { (5) I find that spiritual/religious activities are not very } \\
\text { fulfilling (e.g., prayer, worship, Bible reading) }\end{array}$ & 0 & 1 & 2 & 3 & 4 \\
\hline (6) I find it impossible to pray. & 0 & 1 & 2 & 3 & 4 \\
\hline $\begin{array}{l}\text { (7) I struggle with accepting how a good God allows bad } \\
\text { things to happen. }\end{array}$ & 0 & 1 & 2 & 3 & 4 \\
\hline (8) I find it difficult to surrender my life to God. & 0 & 1 & 2 & 3 & 4 \\
\hline (9) I don't feel as comforted by church fellowship as I used to. & 0 & 1 & 2 & 3 & 4 \\
\hline (10) I can't help feeling angry with God. & 0 & 1 & 2 & 3 & 4 \\
\hline
\end{tabular}


Table A1. Cont.

Items

Not at all A little Somewhat Mostly Very true true true True definitely true

(11) I don't feel very much like joining in fellowship to

$\begin{array}{lllll}0 & 1 & 2 & 3 & 4\end{array}$
praise God or to glorify Him.

(12) The strong guiding light of my faith has grown dim and I feel lost.

(13) I'm confused as to why God would let this happen.

(14) I have lost my desire to worship.

(15) I find it impossible to worship.

(16) I feel my loss is unfair.

(17) I sense the absence of God more than I do the presence of God.

(18) I am a faithful believer, so I don't understand why God

$\begin{array}{lllll}0 & 1 & 2 & 3 & 4\end{array}$
did not protect me.

Note: A sum of all items can be taken to compute a total ICSG score. Likewise, items 1, 4, 7, 10, 13, 16, and 18 can be summed to compute the Insecurity with God subscale, and items 2, 3, 5, 6, 8, 9, 11, 12, 14, 15 and 17 can be summed to compute the Disruption in Religious Practice subscale.

\section{Conflicts of Interest}

The authors declare no conflict of interest.

\section{References}

1. George A. Bonanno, and Stacey Kaltman. "The Varieties of Grief Experience." Clinical Psychology Review 21 (2001): 705-34.

2. George A. Bonanno, and Anthony D. Mancini. "Bereavement-related Depression and PTSD: Evaluating Interventions." In Psychological Interventions in Times of Crisis. Edited by Laura Barbanel and Robert J. Sternberg. New York: Springer, 2006, pp. 37-55.

3. Holly G. Prigerson, Ellen Frank, Stanislav V. Kasl, Charles F. Reynolds, Barbara Anderson, George S. Zubenko, Patricia R. Houck, Charles J. George, and David J. Kupfer. "Complicated Grief and Bereavement Related Depression as Distinct Disorders: Preliminary Empirical Validation in Elderly Bereaved Spouses.” American Journal of Psychiatry 152 (1995): 22-30.

4. Margaret Katherine Shear, Naomi Simon, Melanie Wall, Sidney Zisook, Robert A. Neimeyer, Naihua Duan, Charles Reynolds, Barry Lebowitz, Sharon Sung, Angela Ghesquiere, et al. "Complicated Grief and Related Bereavement Issues for DSM-5." Depression and Anxiety 28 (2011): 103-17.

5. Paul A. Boelen, and Holly G. Prigerson. "The Influence of Symptoms of Prolonged Grief Disorder, Depression, and Anxiety on Quality of Life among Bereaved Adults." European Archives of Psychiatry and Clinical Neuroscience 257 (2007): 444-52.

6. Robert A. Neimeyer. "Prolonged grief disorder." In Encyclopedia of Death and the Human Experience. Edited by Clifton Bryant and Dennis Peck. Thousand Oaks: Sage, 2008. 
7. American Psychiatric Association. The Diagnostic and Statistical Manual of Mental Disorders, 5th ed. Washington, D.C.: American Psychiatric Association, 2013.

8. Joseph M. Currier, Jason M. Holland, Rachel A. Coleman, and Robert A. Neimeyer. "Bereavement Following Violent Death: An Assault on Life and Meaning." In Perspectives on Violence and Violent Death. Edited by Robert Stevenson and Gerry Cox. Amityville: Baywood, 2007.

9. Jason M. Holland, and Robert A. Neimeyer. "An Examination of Stage Theory of Grief among Individuals Bereaved by Natural and Violent Causes: A Meaning-Oriented Contribution." Omega: Journal of Death and Dying 61 (2010): 103-20.

10. Bureau of Justice Statistics. Homicide Trends in the U.S. : Trends by Race. Rockville: National Criminal Justice Reference Service, 2010. Available online: http://www.bjs.gov/content/pub/ pdf/htius.pdf (accessed on 9 November 2014).

11. Joseph M. Currier, Jason M. Holland, and Robert A. Neimeyer. "Sense-making, Grief, and the Experience of Violent Loss: Toward a Mediational Model." Death Studies 30 (2006): 403-28.

12. Susan Kwilecki. "Religion and Coping: A Contribution from Religious Studies." Journal for the Scientific Study of Religion 43 (2004): 477-89.

13. Christina M. Puchalski. "Spirituality and End-of-Life Care: A Time for Listening and Caring." Journal of Palliative Medicine 5 (2002): 289-94

14. Judith C. Hays, and Cristina C. Hendrix. "The Role of Religion in Bereavement." In Handbook of Bereavement Research and Practice: Advances in Theory and Intervention. Edited by Margaret Stroebe, Robert O. Hansson, Wolfgang Stroebe and Henk Schut. Washington, D.C.: American Psychological Association, 2008, pp. 327-48.

15. Jennifer H. Wortmann, and Crystal L. Park. "Religion and Spirituality in Adjustment Following Bereavement: An Integrative Review." Death Studies 32 (2008): 703-36.

16. Robert J. Taylor, Linda Chatters, and Jeff Levin. Religion in Lives of African Americans: Social, Psychological, and Health Perspectives. Thousand Oaks: Sage Publications, 2004.

17. Ronald K. Barrett, and Karen S. Heller. "Death and Dying in the Black Experience." Journal of Palliative Medicine 5 (2002): 793-99.

18. Ronald K. Barrett. "Contemporary African-American Funeral Rites and Traditions." In The Path Ahead: Readings in Death and Dying. Edited by Lynn DeSpelder and Albert L. Strickland. Mountain View: Mayfield, 1995, pp. 80-92.

19. Julie Juola Exline, and Ephraim Rose. "Religious and Spiritual Struggles." In Handbook of the Psychology of Religion and Spirituality. Edited by Raymond Paloutzian and Crystal Park. New York: Guilford Press, 2005, pp. 315-30.

20. Jeffrey Bishop. The Anticipatory Corpse: Medicine, Power, and the Care of the Dying. Notre Dame: University of Notre Dame Press, 2011.

21. Kenneth J. Doka, and Terry L. Martin. Grieving Beyond Gender: Understanding the Ways Men and Women Mourn. New York: Routledge, 2010.

22. Wendy G. Lichtenthal, Dean G. Cruess, and Holly G. Prigerson. "A Case for Establishing Complicated Grief as a Distinct Mental Disorder in DSM-V." Clinical Psychology Review 24 (2004): 637-62. 
23. Holly G. Prigerson, Margaret Katherine Shear, Selby C. Jacobs, Charles F. Reynolds III, Paul K. Maciejewski, Jonathan R. Davidson, Robert A. Rosenheck, Paul A. Pilkonis, Camille B. Wortman, Janet B. Williams, et al. "Consensus Criteria for Traumatic Grief: A Preliminary Empirical Test." British Journal of Psychiatry 174 (1999): 67-73.

24. Donald Edmondson, Crystal L. Park, Stephenie R. Chaudoir, and Jennifer H. Wortmann. "Death without God Religious Struggle, Death Concerns, and Depression in the Terminally III." Psychological Science 19 (2008): 754-58.

25. Peter C. Hill, and Kenneth I. Pargament. "Advances in the Conceptualization and Measurement of Religion and Spirituality: Implications for Physical and Mental Health Research." Psychology of Religion and Spirituality 1 (2008): 2-17.

26. Laurie A. Burke, Robert A. Neimeyer, Meghan E. McDevitt-Murphy, Maria R. Ippolito, and J. Matthew Roberts. "Faith in the Wake of Homicide: Religious Coping and Bereavement Distress in an African American Sample." International Journal for the Psychology of Religion 21 (2011): 289-307.

27. George A. Bonanno, Yuval Neria, Anthony Mancini, Karin G. Coifman, Brett Litz, and Beverly Insel. "Is There More to Complicated Grief than Depression and Posttraumatic Stress Disorder? A Test of Incremental Validity." Journal of Abnormal Psychology 116 (2007): 342-51.

28. Holly G. Prigerson, Mardi J. Horowitz, Selby C. Jacobs, Colin M. Parkes, Mihaela Aslan, Karl Goodkin, Beverley Raphael, Samuel J. Marwit, Camille B. Wortman, Robert A. Neimeyer, et al. "Prolonged Grief Disorder: Psychometric Validation of Criteria Proposed for DSM-V and ICD-11." PLOS Medicine 6 (2009): 1-12.

29. Holly G. Prigerson, and Selby C. Jacobs. "Traumatic Grief as a Distinct Disorder: A Rationale, Consensus Criteria, and a Preliminary Empirical Test." In Handbook of Bereavement Research. Edited by Margaret Stroebe, Robert O. Hansson, Wolfgang Stroebe and Henk Schut. Washingon, D.C.: American Psychological Association, 2001, pp. 613-45.

30. Jason M. Holland, Robert A. Neimeyer, Paul A. Boelen, and Holly G. Prigerson. "The Underlying Structure of Grief: A Taxometric Investigation of Prolonged and Normal Reactions to Loss." Journal of Psychopathology and Behavioral Assessment 31 (2009): 190-201.

31. Benjamin R. Goldsmith, Sean Morrison, Lauren C. Vanderwerker, and Holly G. Prigerson. "Elevated Rates of Prolonged Grief Disorder in African Americans." Death Studies 32 (2008): 352-65.

32. Nancy J. Keesee, Joseph M. Currier, and Robert A. Neimeyer. "Predictors of Grief Following the Death of One's Child: The Contribution of Finding Meaning." Journal of Clinical Psychology 64 (2008): 1145-63.

33. Margaret Katherine Shear, Carlos Jackson, Susan Essock, Sheila Donahue, and Chip Felton. "Screening for Complicated Grief among Project Liberty Service Recipients 18 Months after September 11, 2001.” Psychiatric Services 57 (2006): 1291-97.

34. Meghan E. McDevitt-Murphy, Robert A. Neimeyer, Laurie A. Burke, Joah L. Williams, and Katherine Lawson. "The Toll of Traumatic Loss in African Americans Bereaved by Homicide." Psychological Trauma: Theory, Research, Practice, and Policy 4 (2012): 303-11. 
35. Ann M. Mitchell, Yookyung Kim, Holly G. Prigerson, and MaryKay Mortimer-Stephens. "Complicated Grief in Survivors of Suicide." Crisis: The Journal of Crisis Intervention and Suicide Prevention 25 (2004): 12-18.

36. Louis A. Gamino, Kenneth W. Sewell, and Larry W. Easterling. "Scott and White Grief Study_Phase 2: Toward an Adaptive Model of Grief." Death Studies 24 (2000): 633-60.

37. Wendy G. Lichtenthal, Joseph M. Currier, Robert A. Neimeyer, and Nancy J. Keesee. "Sense and Significance: A Mixed Methods Examination of Meaning Making after the Loss of One's Child." Journal of Clinical Psychology 66 (2010): 791-812.

38. Kenneth D. Kochanek, Sherry L. Murphy, Robert N. Anderson, and Chester Scott. "Deaths: Final Data for 2002." National Vital Statistics Reports 53 (2004): 1-116.

39. Laurie A. Burke, and Robert A. Neimeyer. "Prospective Risk Factors for Complicated Grief: A Review of the Empirical Literature." In Complicated Grief: Scientific Foundations for Health Care Professionals. Edited by Margaret Stroebe, Henk Schut, Paul Boelen and Jan van den Bout. Washington, D.C.: American Psychological Association, 2013, pp. 145-61.

40. George A. Bonanno. "Loss, Trauma, and Human Resilience: Have We Underestimated the Human Capacity to Thrive After Extremely Aversive Events?" American Psychologist 59 (2004): $20-28$.

41. Charles S. Carver, Michael F. Scheier, and Jagdish K. Weintraub. "Assessing Coping Strategies: A Theoretically Based Approach.” Journal of Personality and Social Psychology 56 (1989): 267-83.

42. Kenneth I. Pargament, Bruce W. Smith, Harold G. Koenig, and Lisa Perez. "Patterns of Positive and Negative Religious Coping with Major Life Stressors." Journal for the Scientific Study of Religion 37 (1998): 710-24.

43. Judith Hills, Judith A. Paice, Jacqueline R. Cameron, and Susan Shott. "Spirituality and Distress in Palliative Care Consultation.” Journal of Palliative Medicine 8 (2005): 782-88.

44. Kenneth I. Pargament, Harold G. Koenig, Nalini Tarakeshwar, and June Hahn. "Religious Struggle as a Predictor of Mortality among Medically Ill Elderly Patients: A 2-year Longitudinal Study." Archives of Internal Medicine 161 (2001): 1881-85.

45. Catherine H. Stein, Kristen M. Abraham, Erin E. Bonar, Christine E. McAuliffe, Wendy R. Fogo, David A. Faigin, Hisham Abu Raiya, and Danielle N. Potokar. "Making Meaning From Personal Loss: Religious, Benefit Finding, and Goal-Oriented Attributions." Journal of Loss and Trauma 14 (2009): 83-100.

46. Kenneth I. Pargament, Harold G. Koenig, and Lisa M. Perez. "The Many Methods of Religious Coping: Development and Initial Validation of the RCOPE." Journal of Clinical Psychology 56 (2000): 519-43.

47. Arndt Büssing, and Harold G. Koenig. "Spiritual Needs of Patients with Chronic Diseases." Religions 1 (2010): 18-27.

48. Daniel N. McIntosh, Roxane Cohen Silver, and Camille B. Wortman. "Religion's Role in Adjustment to a Negative Life Event: Coping with the Loss of a Child." Journal of Personality and Social Psychology 65 (1993): 812-21.

49. Mark D. Reed. "Sudden Death and Bereavement Outcomes: The Impact of Resources on Grief Symptomatology and Detachment." Suicide and Life-Threatening Behavior 23 (1993): 204-20. 
50. Darren E. Sherkat, and Mark D. Reed. "The Effects of Religion and Social Support on Self-Esteem and Depression among the Suddenly Bereaved." Social Indicators Research 26 (1992): 259-75.

51. Virginia E. Richardson, and Shantha Balaswamy. "Coping with Bereavement among Elderly Widowers." Omega: Journal of Death and Dying 43 (2001): 129-44.

52. Laurie A. Burke, Robert A. Neimeyer, and Meghan E. McDevitt-Murphy. "African American Homicide Bereavement: Aspects of Social Support that Predict Complicated Grief, PTSD, and Depression." Omega: Journal of Death and Dying 61 (2010): 1-24.

53. Kathleen L. Meert, Celia S. Thurston, and Ronald Thomas. "Parental Coping and Bereavement Outcome after the Death of a Child in the Pediatric Intensive Care Unit." Pediatric Critical Care Medicine 2 (2001): 324-28.

54. Nalini Tarakeshwar, Nathan Hansen, Arlene Kochman, and Kathleen J. Sikkema. "Gender, Ethnicity and Spiritual Coping among Bereaved HIV-positive Individuals." Mental Health, Religion \& Culture 8 (2005): 109-25.

55. Miriam J. Anderson, Samuel J. Marwit, Brian Vandenberg, and John T. Chibnall. "Psychological and Religious Coping Strategies of Mothers Bereaved by the Sudden Death of a Child." Death studies 29 (2005): 811-26.

56. Martie P. Thompson, and Paula J. Vardaman. "The Role of Religion in Coping with the Loss of a Family Member to Homicide.” Journal for the Scientific Study of Religion 36 (1997): 44-51.

57. Kenneth I. Pargament, David S. Ensing, Kathryn Falgout, Hannah Olsen, Barbara Reilly, Kimberly Van Haitsma, and Richard Warren. "God Help Me (I): Religious Coping Efforts as Predictors of the Outcomes to Significant Negative Life Events." American Journal of Community Psychology 18 (1990): 793-824.

58. Jeremy P. Cummings, and Kenneth I. Pargament. "Medicine for the Spirit: Religious Coping in Individuals with Medical Conditions." Religions 1 (2010): 28-53.

59. Margaret Katherine Shear, Sharon Dennard, Montele Crawford, Mario Cruz, Bonnie Gorscak, and Linda Oliver. "Developing a Two-session Intervention for Church-based Bereavement Support: A Pilot Project." Paper presented at the 22nd International Society Traumatic Stress Studies, Hollywood, CA, USA, 4-7 November 2006, pp. 5-7.

60. Michelle Batten, and Kevin Ann Oltjenbruns. "Adolescent Sibling Bereavement as a Catalyst for Spiritual Development: A Model for Understanding.” Death Studies 23 (1999): 529-46.

61. Julie Juola Exline, and Alyce Martin. "Anger toward God: A New Frontier in Forgiveness Research." In Handbook of Forgiveness. Edited by Everett Worthington. New York: Routledge 2005, pp. 73-88.

62. Robert A. Neimeyer, and Laurie A. Burke. "Complicated Grief in the Aftermath of Homicide: Spiritual Crisis and Distress in an African American Sample.” Religions 2 (2011): 145-64.

63. Joseph M. Currier, Robert A. Neimeyer, and Jeffrey S. Berman. "The Effectiveness of Psychotherapeutic Interventions for Bereaved Persons: A Comprehensive Quantitative Review." Psychological Bulletin 134 (2008): 648-61.

64. Margaret Katherine Shear, Paul Boelen, and Robert A. Neimeyer. "Treating Complicated Grief: Converging Approaches." Grief and Bereavement in Contemporary Society: Bridging Research 
and Practice. Edited by Robert Neimeyer, Darcy Harris, Howard Winokuer and Gordon Thornton. New York: Routledge, 2011, pp. 139-62.

65. Wendy G. Lichtenthal, Laurie A. Burke, and Robert A. Neimeyer. "Religious Coping and Meaning-making Following the Loss of a Loved One." Counseling and Spirituality 30 (2011): 113-36.

66. Rachel A. Coleman, and Robert A. Neimeyer. "Measuring Meaning: Searching for and Making Sense of Spousal Loss in Late-Life." Death Studies 34 (2010): 804-34.

67. Robert Marrone. "Dying, Mourning, and Spirituality: A Psychological Perspective." Death Studies 23 (1999): 495-519.

68. Kenneth I. Pargament, Nichole A. Murray-Swank, Gina M. Magyar, and Gene G. Ano. "Spiritual Struggle: A Phenomenon of Interest to Psychology and Religion." In Judeo-Christian Perspectives on Psychology: Human Nature, Motivation, and Change. Washington, D.C.: American Psychological Association, 2005, pp. 245-68.

69. Kelly M. McConnell, Kenneth I. Pargament, Christopher G. Ellison, and Kevin J. Flannelly. "Examining the Links between Spiritual Struggles and Symptoms of Psychopathology in a National Sample.” Journal of Clinical Psychology 62 (2006): 1469-84.

70. Laurie A. Burke, and Robert A. Neimeyer. "Complicated Spiritual Grief I: Relation to Complicated Grief Symptomatology Following Violent Death Bereavement." Death Studies 38 (2014): 259-67.

71. Laurie A. Burke, Robert A. Neimeyer, Amanda J. Young, Elizabeth Piazza Bonin, and Natalie L. Davis. "Complicated Spiritual Grief II: A Deductive Inquiry Following the Loss of a Loved One." Death Studies 38 (2014): 268-81.

72. W. James Potter, and Deborah Levine-Donnerstein. "Rethinking Validity and Reliability in Content Analysis." Journal of Applied Communication Research 27 (1999): 258-84.

73. Hsiu-Fang Hsieh, and Sarah E. Shannon. "Three Approaches to Qualitative Content Analysis." Qualitative Health Research 15 (2005): 1277-88.

74. Phillipp Mayring. "Qualitative Content Analysis.” Available online: http://www.qualitativeresearch.net/index.php/fqs (accessed on 4 June 2011).

75. Laurie A. Burke, Robert A. Neimeyer, Jason M. Holland, Sharon Dennard, Linda Oliver, and Margaret Katherine Shear. "Inventory of Complicated Spiritual Grief: Development and Validation of a New Measure." Death Studies 38 (2014): 239-50.

76. Julie Juola Exline, Ann Marie Yali, and William C. Sanderson. "Guilt, Discord, and Alienation: The Role of Religious Strain in Depression and Suicidality." Journal of Clinical Psychology 56 (2000): 1481-96.

77. Julie J. Exline, Crystal L. Park, Joshua M. Smyth, and Michael P. Carey. "Anger toward God: Social-Cognitive Predictors, Prevalence, and Links with Adjustment to Bereavement and Cancer." Journal of Personality and Social Psychology 100 (2011): 129-48.

78. Terry Lynn Gall, Elizabeth Kristjansson, Claire Charbonneau, and Peggy Florack. "A Longitudinal Study on the Role of Spirituality in Response to the Diagnosis and Treatment of Breast Cancer." Journal of Behavioral Medicine 32 (2009): 174-86. 
79. Todd W. Hall, and Keith J. Edwards. "The Spiritual Assessment Inventory: A Theistic Model and Measure for Assessing Spiritual Development." Journal for the Scientific Study of Religion 41 (2002): 341-57.

80. Benjamin T. Wood, Everett L. Worthington, Jr., Julie Juola Exline, Ann Marie Yali, Jamie D. Aten, and Mark R. McMinn. "Development, Refinement, and Psychometric Properties of the Attitudes toward God Scale (ATGS-9)." Psychology of Religion and Spirituality 2 (2010): 148-67.

81. Anna Laurie, and Robert A. Neimeyer. "African Americans in Bereavement: Grief as a Function of Ethnicity." Omega: Journal of Death and Dying 57 (2008): 173-93.

82. David O. Moberg. Spiritual Well-Being. Washington, D.C.: University Press of America, 1979.

83. Robert A. Neimeyer, and Diana Sands. "Meaning Reconstruction in Bereavement: From Principles to Practice." In Grief and Bereavement in Contemporary Society: Bridging Research and Practice. Edited by Robert Neimeyer, Darcy Harris, Howard Winokuer and Gordon Thornton. New York: Routledge, 2011.

84. Laurie A. Burke, Khatijda S. Ali, Karen A. Clark, and Robert A. Neimeyer. "Spiritual Meaning Making in Family Members of Terminally Ill Veterans.” Unpublished work, 2014.

85. Michelle J. Pearce, Debra L. Wiegand, Laurie A. Burke, and Robert A. Neimeyer. "Spiritual Adaptation to Loss: A Pilot Intervention for Spiritually Inclined Grievers.” Unpublished work, 2014.

(C) 2014 by the authors; licensee MDPI, Basel, Switzerland. This article is an open access article distributed under the terms and conditions of the Creative Commons Attribution license (http://creativecommons.org/licenses/by/4.0/). 